\title{
Quantifying and Incentivizing Exploration of Reputable Sources for Argument Formation in an Online Discussion Forum
}

\author{
L. Square ${ }^{1,2^{*}}$, V. van der Heyde ${ }^{1}$ and D. Smith \\ ${ }^{1}$ University of the Western Cape, Robert Sobukwe Road, Bellville, South Africa \\ ${ }^{2}$ North-West University, Potchefstroom, South Africa \\ Lynndle.Square@nwu.ac.za
}

\begin{abstract}
Nuclear powerforms part of the first-year physics undergraduate course workin the extended curriculum program at the University of the Western Cape. This investigation intends to assist students in mastering their understanding of how nuclear power works through the development of critical thinking skills around the topic and to create awareness among students of the implications of expanding a nuclear power footprint. Through debate, students in this course investigate the impact of South Africa increasing its nuclear footprint within a global context. In this work, students were encouraged to explore publications and reputable websites surrounding this topic and based on their findings formulate arguments. The authors conceptualized and developed a Sakai tool (based on Learning Tools Interoperability), called Reference Register (RR) to compliment the work. RR stores the reference uploaded by each student, shares uploaded literature resources to the group members, and quantifies the number of times a student uses a reference when presenting their argument. The incorporation of the RR was intended to encourage students to formulate arguments based on well-founded literature. Authors sort to investigate in which ways and to what extent does an online discussion forum facilitate students becoming ethically, environmentally, and socially aware in the area of nuclear energy and to assist students in becoming better in their professional communication skills. The outcome of this student engagement included students becoming familiar with what constitutes a well-formulated scientific argument based on a literature review, group engagement, becoming aware of South African current affairs regarding nuclear power, and its social and economic impact.
\end{abstract}

Keywords: online debate; undergraduate physics; reference register; Sakai; e-learning

\section{Introduction}

The University of the Western Cape (UWC) is one of 26 public universities in South Africa. At the University of the Western Cape (UWC) strategic plans in learning and teaching have led to the outcome of the Charter of Graduate Attributes (UWC, 2009). The Charter intends to ensure that graduates from UWC are more employable and possess desirable graduate attributes on the completion of their studies. Part of the Charter includes a set of overarching skills and abilities.

The skills embedded in this class activity for first-year physics undergraduate students' address critical thinking and allowing students to become relevantly literate. It intends to expose them to an application of physics, nuclear power generation and in doing so, for a student to become ethically, environmentally, and socially aware within this context. The activity uses the online debate platform to assist students in becoming skilled communicators. At the time of this study using online activities are relatively new at UWC. The difficulty in the rapid transition stems from either or both off campus internet connectivity and or the lack of a suitable device among a vast number of students. The Sakai tool, Reference Register (RR), conceptualized and developed by the authors was created to encourage students to explore published texts and then to incentivize well based literature-reviewed arguments.

This group activity is envisaged to enhance the students' learning in the form of understanding of content and to build transferable skills. The discussion forum allows for cooperative learning where it is hoped to maximize the students' own and each other's learning as described by (Johnson, et al., 2008). In a later paper Johnson (Johnson, et al., 2014) states that cooperative learning is defined by and allows for positive interdependence, where students consider that if one performs better then all students engaged will.

Debates in more technical subjects can effectively facilitate critical thinking (Kennedy, 2007). When this takes place in an online forum, the discussion can take place at any time and in any place, thus students have the opportunity to ponder the discussion and to produce detailed and considered reflections. Some of the advantages discussed in papers by Andresen (Andresen, 2009), Fleming (Fleming, 2008), and Hazari (Hazari, 2004) are that students can reflect on the evolving discussion as often as they like. When this is held online the hesitation for exploring debates in a classroom, because it may alienate some students is removed and therefore

CACPIL

Reference this paper: Square, L., van der Heyde, V., and Smith, D., 2021. Quantifying and Incentivizing Exploration of Reputable Sources for Argument Formation in an Online Discussion Forum. The Electronic Journal of e-Learning, 19(3), pp. 209-219, available online at www.ejel.org 
a discussion board can feel more inclusive, students have time to read and review the exchanges of views. Therefore, with this insight, the authors envisaged that this activity would promote accountability and inclusivity which is particularly difficult in larger classrooms. In the University of New South Wales Teachers Assessment Toolkit: Assessing by Discussion Board the following added advantages are;

Students can see and evaluate their peers' posts, and this helps develop a community of inquiry and a more democratic assessment process. When assessed, students are more inclined to contribute actively and productively to the discussion. This leads to comprehensive class discussions, as well as increased opportunities for students to demonstrate the depth of their learning.

In the work by Scott (Scott, 2008) and Paul et al (Paul, 2019), critical thinking involves solving complex problems by raising pivotal questions, gathering appropriate information, disseminating the findings, and communicating the outcomes. Maiorana (Maiorana, 1992) in Scott (Scott, 2008) states: 'the purpose of critical thinking is to use questioning techniques to achieve understanding, evaluate viewpoints, and solve problems', all of which are valuable skills to acquire for any scientist in training. Scott (Scott, 2008) found that the debate process also helps students' master content. Cheese et al (Cheese, 2015) convey in their work that debates stimulate critical thinking and can be a highly effective way to actively engage students in the classroom. At many tertiary institutions classes sizes greater than one hundred students is not unusual and this could be an effective way to get more students to engage with the course work. Shaw (Shaw, 2012) and Zare et al (Zare, 2013) too are convinced that debates stimulate critical thinking and can be a highly effective way to actively engage students in research in the online classroom, mastering the course content and aid in improving the students' communication skills. Zare et al (Zare, 2013) findings included claims that additional benefits of the debates included, boosting the students' confidence, overcoming stage fright, and improving teamwork skills. In the work by Tessier (Tessier, 2009), students value debates for developing their arguing skills, where the Internet was used as a primary source. Later it was discovered that students concluded a source was trustworthy most often by considering the authority of the author. McGreevy et al (McGreevy, 2017) used a virtual online debating platform and the majority of the students in their study found that it to be a non-threatening environment for discussing emotive and difficult issues. Students communicated that it allowed them to see how their peers formed ideas and in turn reflect on how best to express their ideas and formulate an argument. In the book by Davis et al (Davis, 2016) the reasons for incorporating a debate in a teaching platform can be summarised by the following;

- The participants in the debate learn to listen and to engage meaningfully in conversation with those with whom they disagree.

- Debaters learn to identify and confront inconsistencies while exploring the same introspection of their own beliefs and preconceptions.

- Participants in a debate appreciate well thought through arguments, stances and are willing to tackle complex ideas.

- Learners understand the significance of effective communication.

- Debaters learn to assess the objectives and then formulate the processes necessary to achieve them.

This investigation intends to explore the benefits of debates and the benefits of the online forum to enhance the critical thinking skills of first-year physics students and for them to master the course content in the area of nuclear power. The motivation for the development of RR was to create a tool that would guide students to develop structured arguments. The RR allows the course presenter to quantify the number of sources a student used and therefore this can be used, as in this instance, as an assessment criterion.

\section{Research Methodology}

Students in the physics ECP (Extended Curriculum Program) contributed to the nuclear power debate towards the end of the first semester. Physics 151 (2018) consisted of 119 students, where 85\% (101) of the students have agreed to the authors' reporting of the outcome of this study. In class the topics radioactivity, fission, and fusion are explored; these topics served as an introduction to the mechanisms of nuclear power generation and a launchpad for the discussion of whether our country should go ahead and expand the number of nuclear power plants (NPP) it already had.

In class, students are ordinarily divided into groups of three. For this exercise, two groups are put together for the debate and told, which team is for and which team argues against the expansion of nuclear power in South Africa. The first part of the activity is for students to find literature that would assist with their argument. 
Students were then given a week to find suitable literature, upload their references onto the RR and view and familiarise themselves with what the other participants have uploaded. For the debate, a student would only be awarded for using the literature the group submitted to the RR. This would then imply that in each debate group, of six students, each student should have read six papers. Students were given a rubric and the following criteria were emphasised as part of the evaluation of their performance in the debate i.e. The number of times a student's posts a comment is considered (this prevents a student from only posting one long argument), the period over which they post (this prevents a student from logging in the night before and then only spending one day to engage in the activity), how they engage with the other participants in the forum. The students received a rubric that was created by Nandi et al. (Nandi, 2009). A students' final grade then constituted of an assessment using the rubric and the outcome from the RR.

\subsection{Educational Technologies used for Online Debate Forum}

Within Higher Education (HE) learning-and-teaching environments, eLearning is defined as the use of time and space-dependent and independent application(s) intended to effectively distribute a range of multimedia content, such as; lecture material, assessments, communications, and discussions to both academics and students. For this study, the institutional Learning Management System (LMS), branded, iKamva (based on Sakai https://sakaiproject.org) will support the eLearning concept, as well as the integrated eTool, termed, Reference Register (RR).

\subsubsection{Discussion Forum}

The eTool, Discussion Forum (DF) located within iKamva can be used by the academics (and teaching assistants) to create, moderate, manage several online forums/topics and groups within a course. For this research study, the students are split into two main groups (i.e. groups one and two), with further sub-groups for the topic, "nuclear power for the sustainable future in South Africa?". A depiction of the online setup can be viewed in figure one, which displays the main and sub-groups with the number of messages (unread as well). Additionally, the site can also send private messages to group participants, provide feedback, set word counts, permissions, and grade the discussions. DF was used for this study to facilitate and enable communication amongst the ECP students (within their groups) regarding the debatable issue, the use ofnuclear power within South Africa. A depiction of the latter can be seen in Figure 2.

The DF serves as a contributing, communication, reading, and writing eTool within iKamva for both the academics and ECP students. It allows for non-real-time (asynchronous) communication, meaning fewer chances for students to control the interaction within a forum and thus higher probability for fair opportunitiesand easy engagement than in a face-to-face discussion.

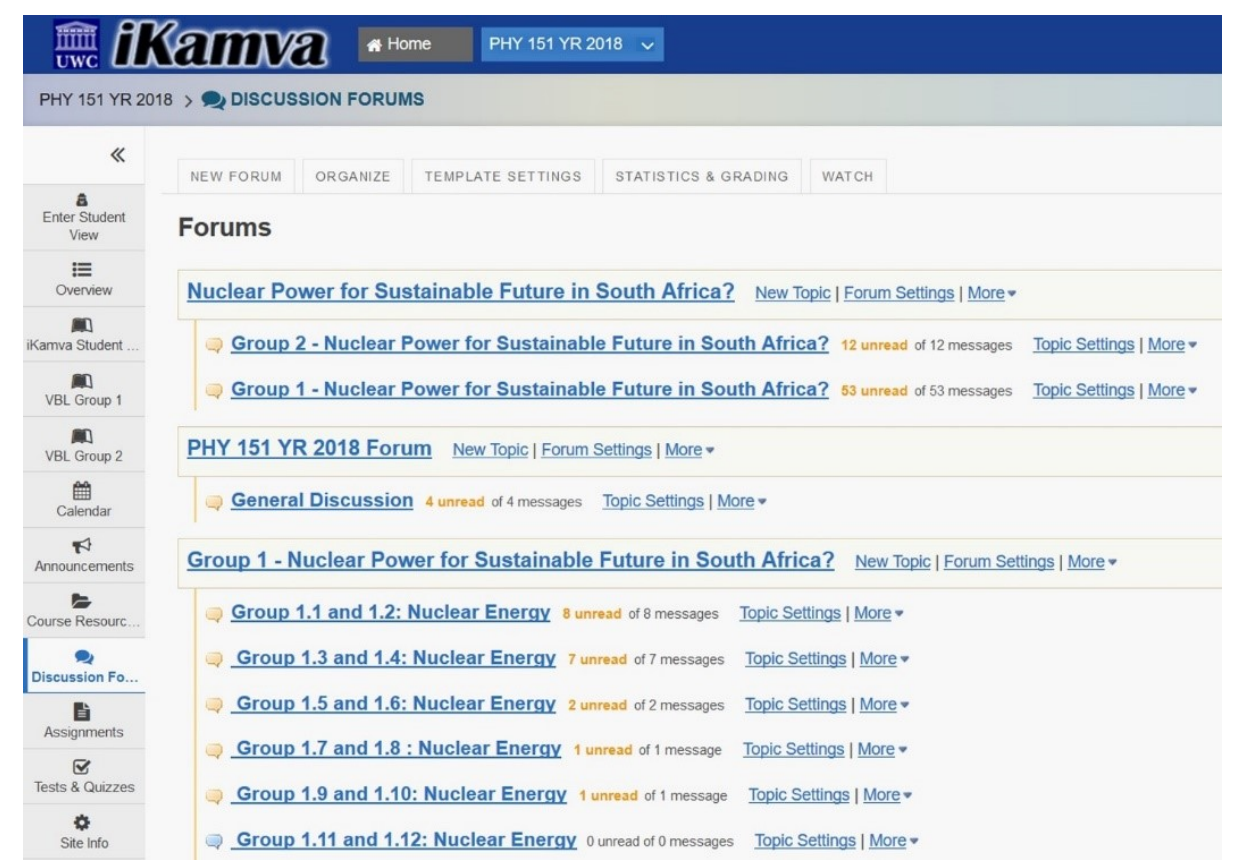

Figure 1: Depiction of Discussion Forum structure which displays two main groups (Group 1 and 2), with related sub-groups 


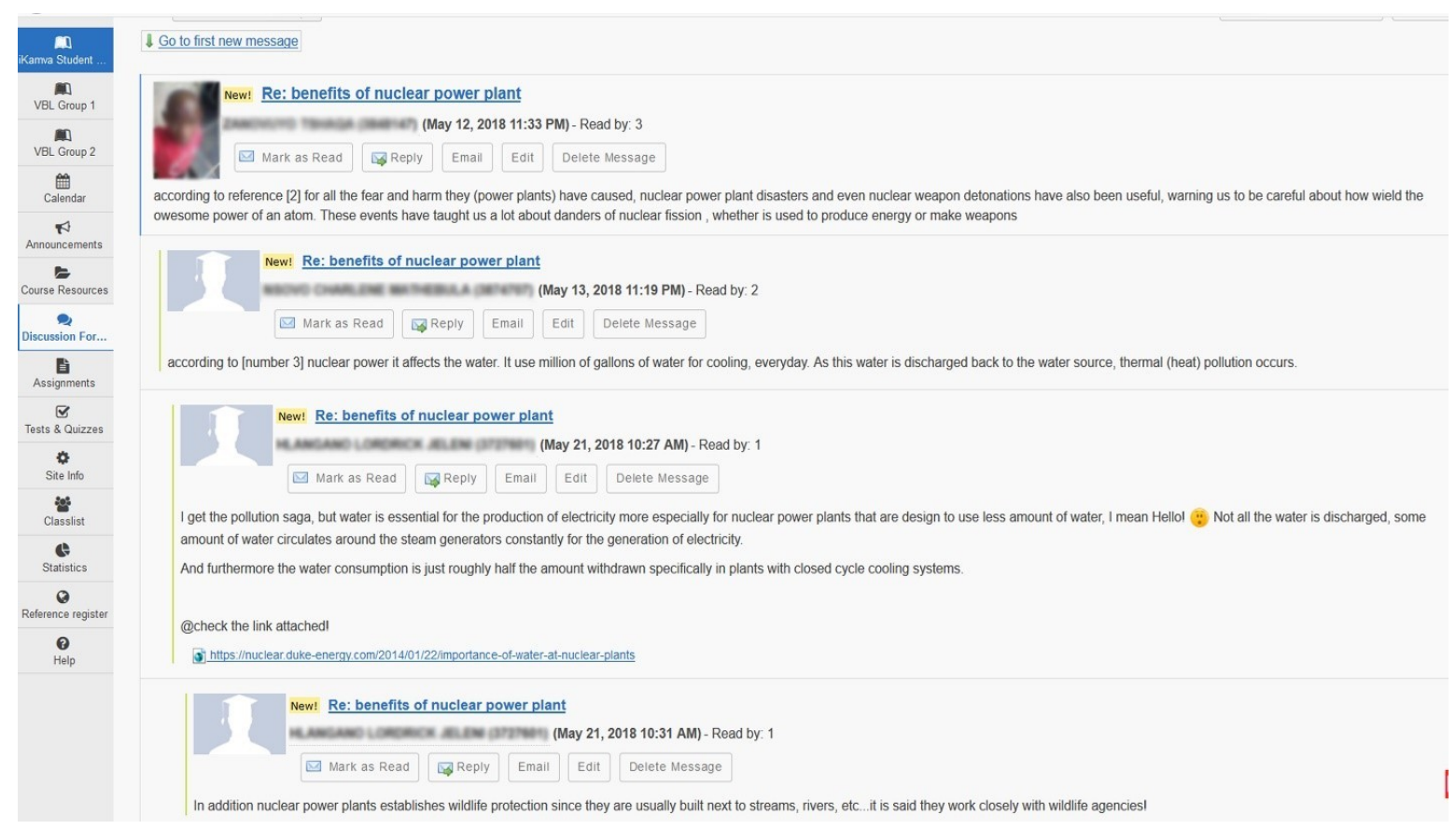

Figure 2: Asynchronous Communication between ECP students engaging with one another on the debatable topic, "Nuclear Power for Sustainable Future in South Africa"

\subsubsection{External Tool: Reference Register}

The RR is a custom-built external tool, used to complement the DF. The R Rallows students to collate their arguments (see Figure 3) and upload their references (see Figure 4) before the start of the debate. Students may also view the references provided by fellow members of their group, thereby familiarising themselves with multiple sources to support their assertions. Given that the debate requires students tospend a considerable amount of time online, the emphasis had been placed on providing a streamlined interface to students to facilitate the collection - and the validation - of their references. Furthermore, the RR serves the teaching staff as well in terms of,

- real-time information on the state of debates is provided via dashboards (see Figure 5),

- it mitigates some of the administrative burdens by analyzing and collating results, and

- allows for the download of all responses contained within the DF, or those responses that are determined to be properly referenced.

As the RR is a custom-built tool, additional functionalities not provided by the LMS can be developed. These include validation of references, automation of processes, sentiment analysis, and custom workflows such as email reminders via integration with third-party services such as Google Apps (Giannakos, 2010; Miranda, 2017; Rubens, 2012).

The efficacy of this work was assessed using the following three measurands:

1. Students experience feedback forms.

2. The online discussion forum analysis and the outcomes from the RR data

3. Assessment of the quality of the debates using the rubric. 


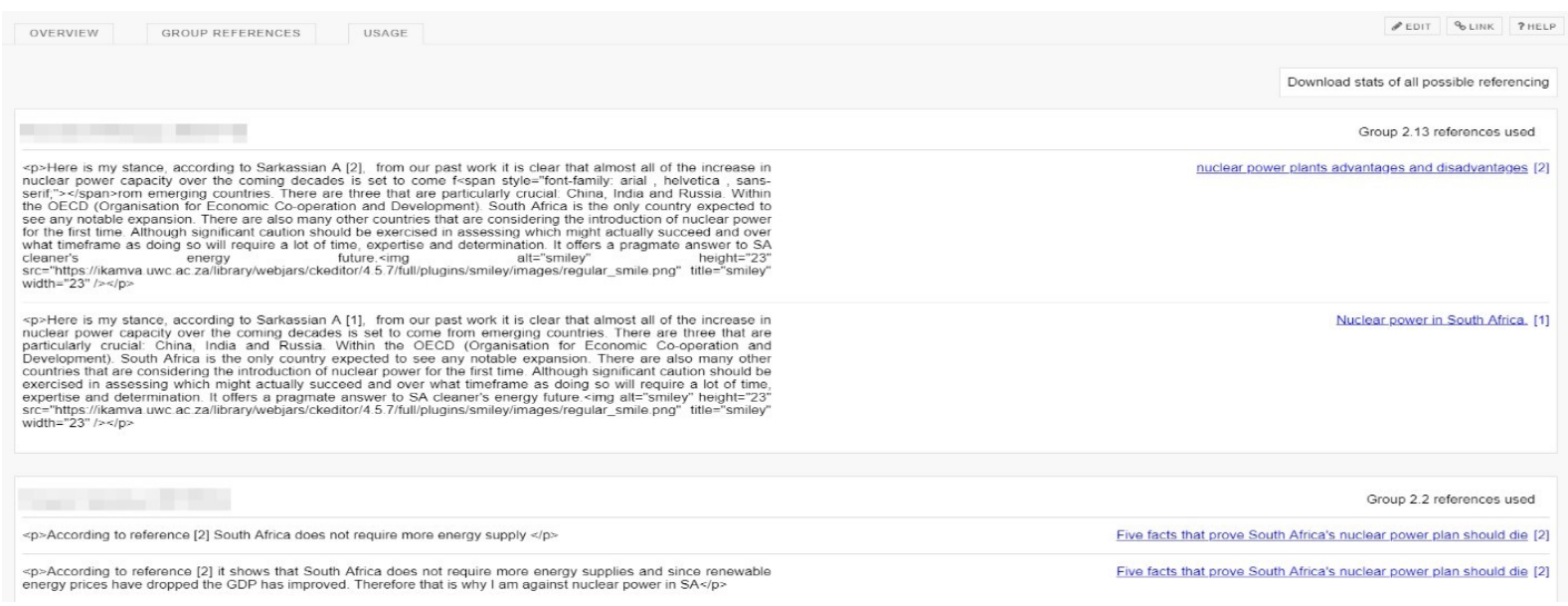

Figure 3: (Administrator interface) Collation of arguments that have been properly referenced. Instead of interrogating each post in the discussion forum, administrators have a single location to view or download all referenced posts

\begin{tabular}{|c|c|c|c|}
\hline OVERVIEW & GROUP REFERENCES & USAGE & \\
\hline \multicolumn{4}{|l|}{ Group 2.1} \\
\hline \multicolumn{4}{|l|}{ Group 2.1} \\
\hline 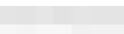 & (1) & & Benefits of nuclear fusion \\
\hline & & & Nuclear can make 'staggering' contribution to GDP, claims \\
\hline \multicolumn{4}{|l|}{ Group 2.11} \\
\hline 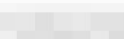 & -1 & & nuclear energy and the fossil fuels \\
\hline 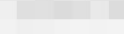 & 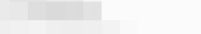 & & Advantages of Nuclear Energy. \\
\hline 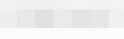 & 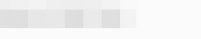 & & Top 10 Advantages of Nuclear Energy. \\
\hline \multicolumn{4}{|l|}{ Group 2.12} \\
\hline 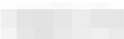 & 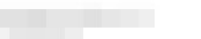 & & The Case For and Against Nuclear Power \\
\hline & (n) & & The risk attached to South Africa's nuclear energy strategy. \\
\hline \multicolumn{4}{|l|}{ Group 2.13} \\
\hline 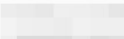 & & & Nuclear power in South Africa. \\
\hline 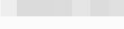 & ( & & nuclear power plants advantages and disadvantages \\
\hline
\end{tabular}

Figure 4: (Administrator interface) Real-time view of group references and reference submitters, filtered by group title. Administrators can interrogate references supplied by specific students or groups

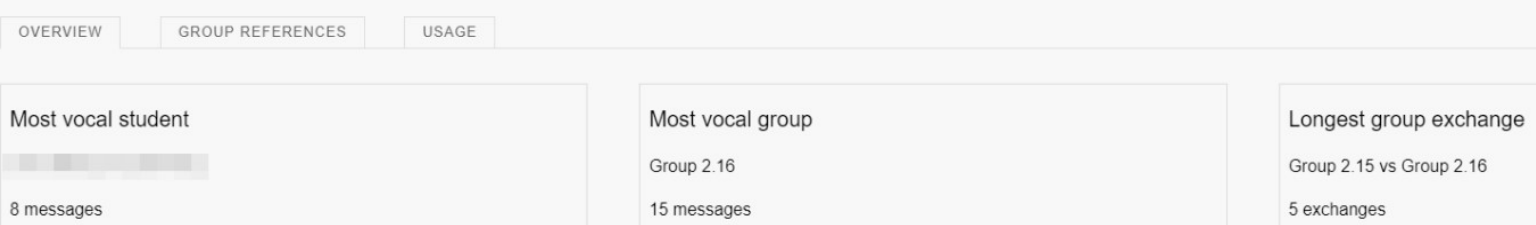

Longest group exchange

Group 2.15 vs Group 2.16

5 exchanges

Figure 5: Simple real-time dashboard displaying useful information on the state of debates. Administrators may use the dashboard for quick indications on the health of the debates, whereas for students, the dashboard acts as a rudimentary gamification interface 


\section{Results}

Physics 151 (2018) consisted of 119 students, where 85\% (101) of the students have agreed to the authors' reporting of the outcome of this study. Of the 101 students, 65 students completed the feedback forms and 53 students participated in the debate.

\subsection{Student Feedback Forms}

This section will present the measurement of the research activity using paper-based student feedback forms. In class when introducing the activity the students were asked if they had ever participated in a debate and only a handful of students could say yes. This prompted a further discussion on debates. In the questionnaire given to the students' the first question the students were asked, and was used to gauge their previous knowledge on the topic, "Before learning about how Nuclear Power works in Physics 151, what were thoughts about the Republic of South Africa (RSA) exploring this as an opportunity for our future energy mix? Did you know that RSA is considering building more NPP?". The results indicated that the majority of students did not know that RSA was exploring the possibility of building more NPP and therefore their only knowledge before the debate was the material discussed in class. In class, the focus was on the mechanics of a nuclear power plant and radioactivity. An hour-long lecture was used to watch a documentary on the Fukushima nuclear power plant failure, we discussed the differences between the Chernobyl incident and Fukushima. Further short discussions included South Africa's current energy mix within the global context and the socio-economic structure surrounding South Africa's natural resources and employment.

The second question, "Did the rubric assist you in preparing a good debate? Explain.". The majority of students found the rubric very helpful as it focused on key aspects of the debate. Furthermore, the students mentioned it assisted them to include references for their claims. However, references are not considered a requirement in the rubric but the incorporation of the RR makes it a requirement. The students were then asked about their experience i.e. "What were the good and not so good experiences using an online forum for discussing the subject matter?". Most students enjoyed the online debate forum, i.e. they felt at ease not having to talk in front of their peers. A small group found the online forum a new and interesting experience. Additionally, a few students complained that the groups they were debating against did not respond in time or not at all. An option going forward would be to allow these students to join an additional group in the event the rest of their group members does not participate.

Despite having provided training, a few students did not understand the layout of the online forum or how to upload their references correctly. A smaller group of students felt disadvantaged because they did not have access to the internet at home and had to stay on campus to regularly engage in the forum. Given the intermittent $\mathrm{Wi}-\mathrm{Fi}$ and the limited number of computer laboratories on campus, this is something to brainstorm in the future. The feedback form then included a Likert chart indicated in table 1.

The final question asked in the feedback form was "Do you have any other feedback for the team?". The responses that came back were that some students would prefer the traditional manner of debating instead of the online version, due to internet access. Students would like a way to monitor or to be notified that other group members posted or responded to their posts. A great recommendation given by the students was that groups should be monitored to ensure that they contribute to the debate and give their arguments. 


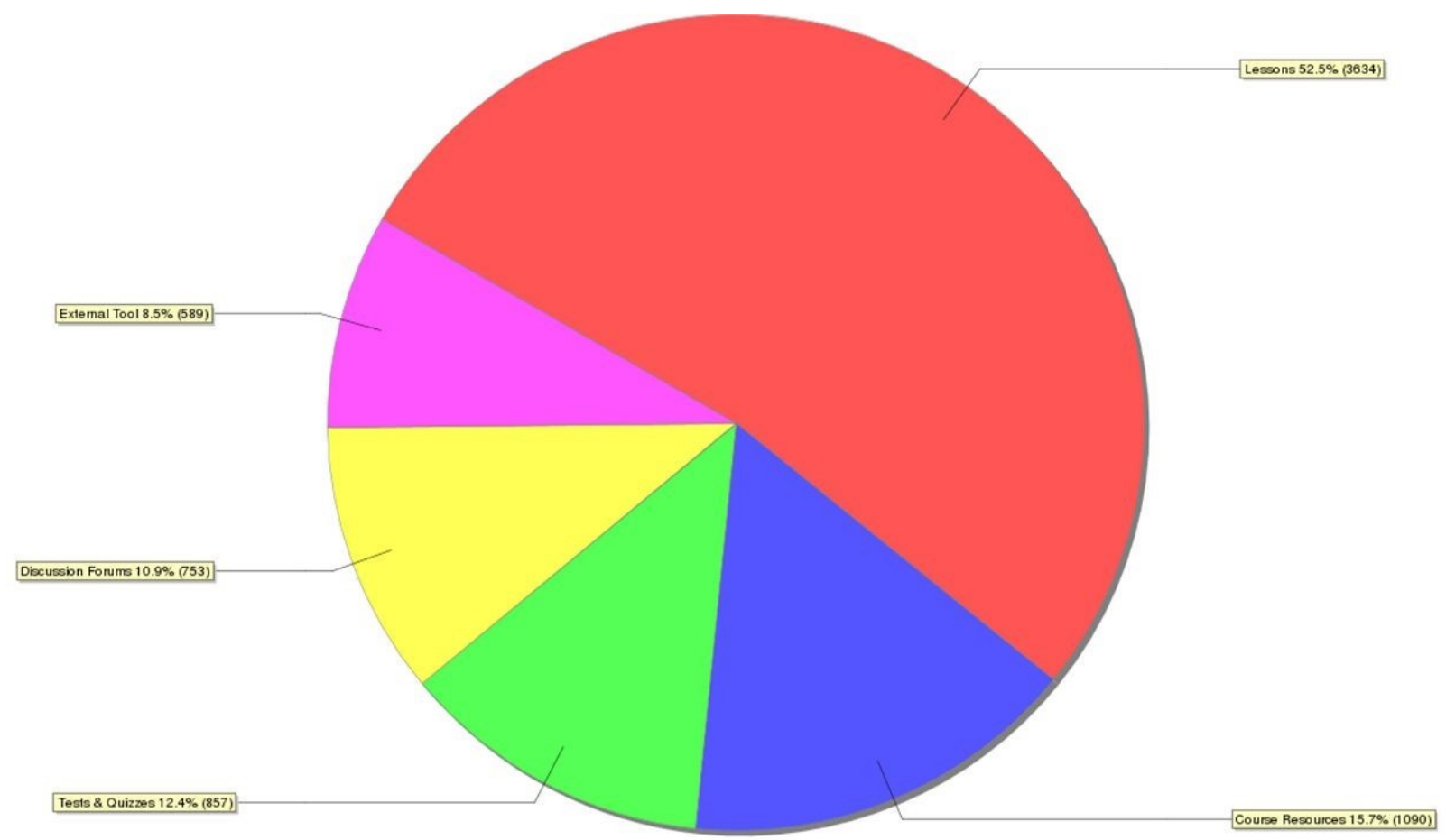

Figure 6: Pie chart displaying the total activity (753) for utilization of Discussion Forum on Learning Management System by the ECP students.

\subsection{Debate online analysis and the outcomes from the RR data}

The graphical representations alongside the statistical information concerning course activity, engagement, and participation for this study were derived from the LMS system.

Figures 6-9 displays, and support the DF responses. These illustrate the total activities for utilization of DF and Reference Register (RR) by the students and the total site visits - and unique visits for the duration of the project (Term 2, 2018). Overall, this stand-alone secondary quantitative data will highlight the visibility (logins) and engagement (within DF) of the students. Figure six displays the total activities by the ECP students (and the most active students) for the utilization of the DF in terms of accessing, reading, -and replying to posts within their groups. A total number of 753 activities were done during the duration of the project, averaging six activities per student. Figure seven reflects visible and engaged students during the first semester, but most importantly note the spike in visits for May 2018 (compared to Feb, Mar, and Apr 2018), as this was the time frame for the project. Note that the visits are defined as more than one visit per day per student, whereas unique visitors is just one login for the day per student. As seen from the bar chart, there is an increase in terms of visits for each month, whereas the number of unique visitors is roughly the same each month. Figure 8 displays the total activities by the ECP students (and the most active students) for the utilization of the external LTI tool, termed, Reference Register. A total number of 589 activities were done during the duration of the project, averaging 5 activities per student. 


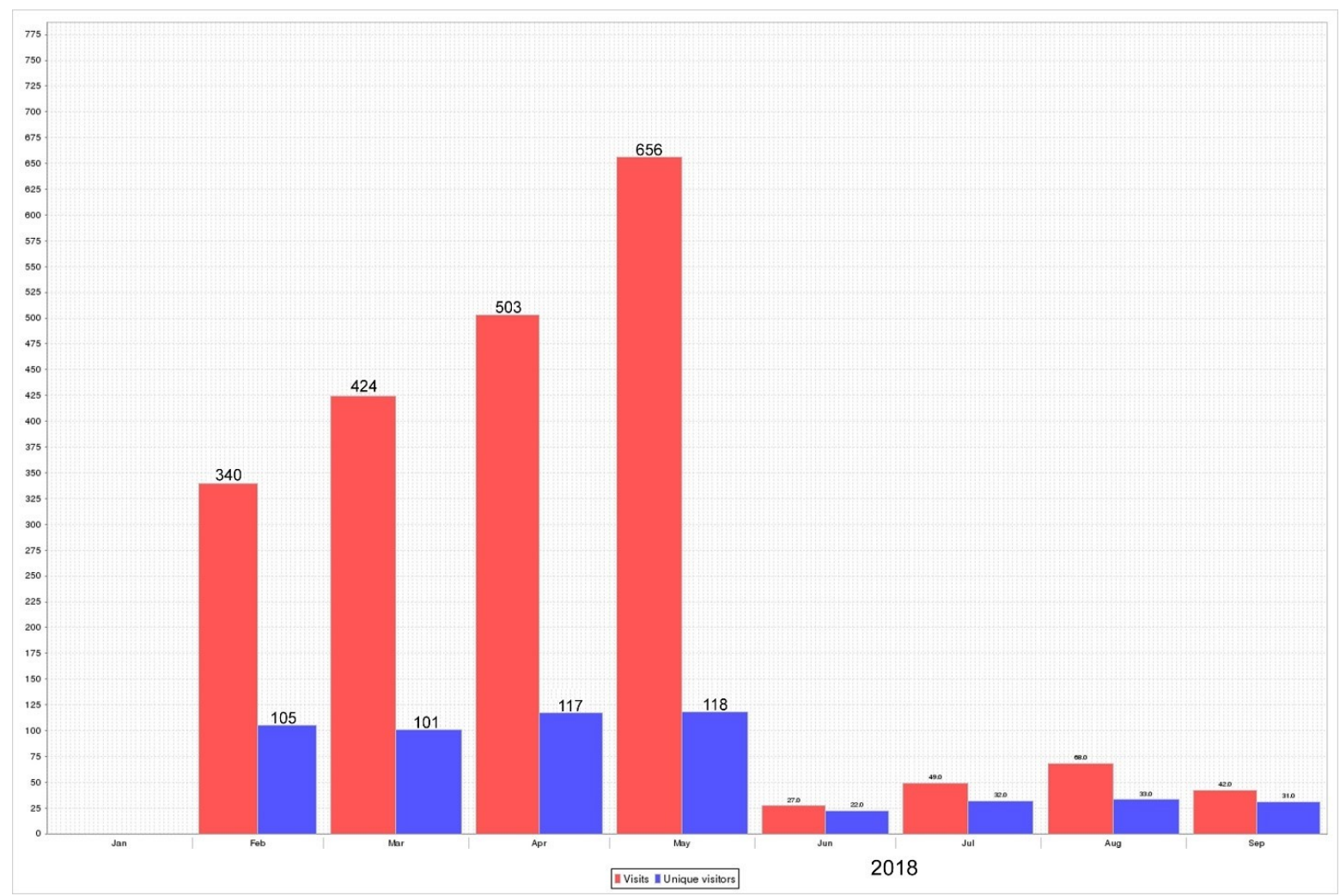

Figure 7: Bar chart displaying the number of visits and unique visitors by ECP students during the time frame, Feb - June 2018.

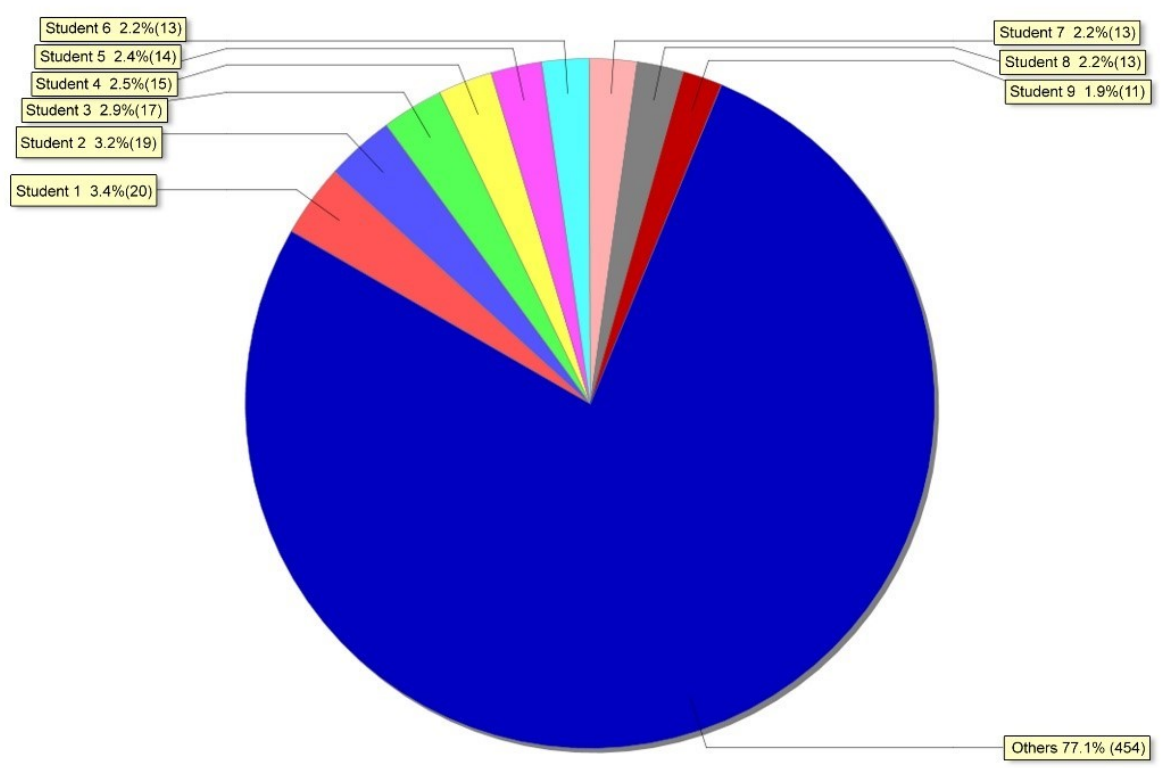

Figure 8: Pie chart displaying the total activity (589) for utilization of the external LTI tool, Reference Register on the LMS by the ECP students 
Furthermore, Figure nine is a pie chart displaying the numerous eTools used on the LMS for the first semester of the academic year and can be seen that the DF and External Tool (RR) eTools comprised of 10.9\% (753) and $8.5 \%$ (589) of the total usage of eTools, respectively, which coincides with the totals in Figure six and eight, respectively.

For the debate, 53 people participated. Of the 53, 2 people just entered one line to say hello. 30 of the 50 people then managed to use some form of in-text referencing either the "[]" or " () " brackets. However, when going through the data manually an extra 10 students used some other forms of referencing. The confusion could be a result of different formats used across disciplines. When comparing the results of the students who managed to use a form of in-text referencing and their performance as an outcome from the assessment using the rubric there is a $70 \%$ correlation. Where a student is considered to have done well in the referencing (RR) component when they use most/ or all the literature provided by their group. One student managed to score well using the rubric, however, it did not include any citations in their argument. On further investigation when reading the debate posts it becomes very clear that their views are an accumulation of reading reviews from many sources.

\subsection{Assessment of the quality of the debates using the rubric.}

The rubric created by Nandi et al (Nandi, 2009), helped students and assessors clarify the criterion for a good debate discussion. Students would refer to one another in text and when reviewing their work it becomes clear how this helps with the flow of the debate. The rubric, because of the many criteria ensured the longevity of the debate specifically considering the objective measures, i.e. participation rates and consistency of participation.

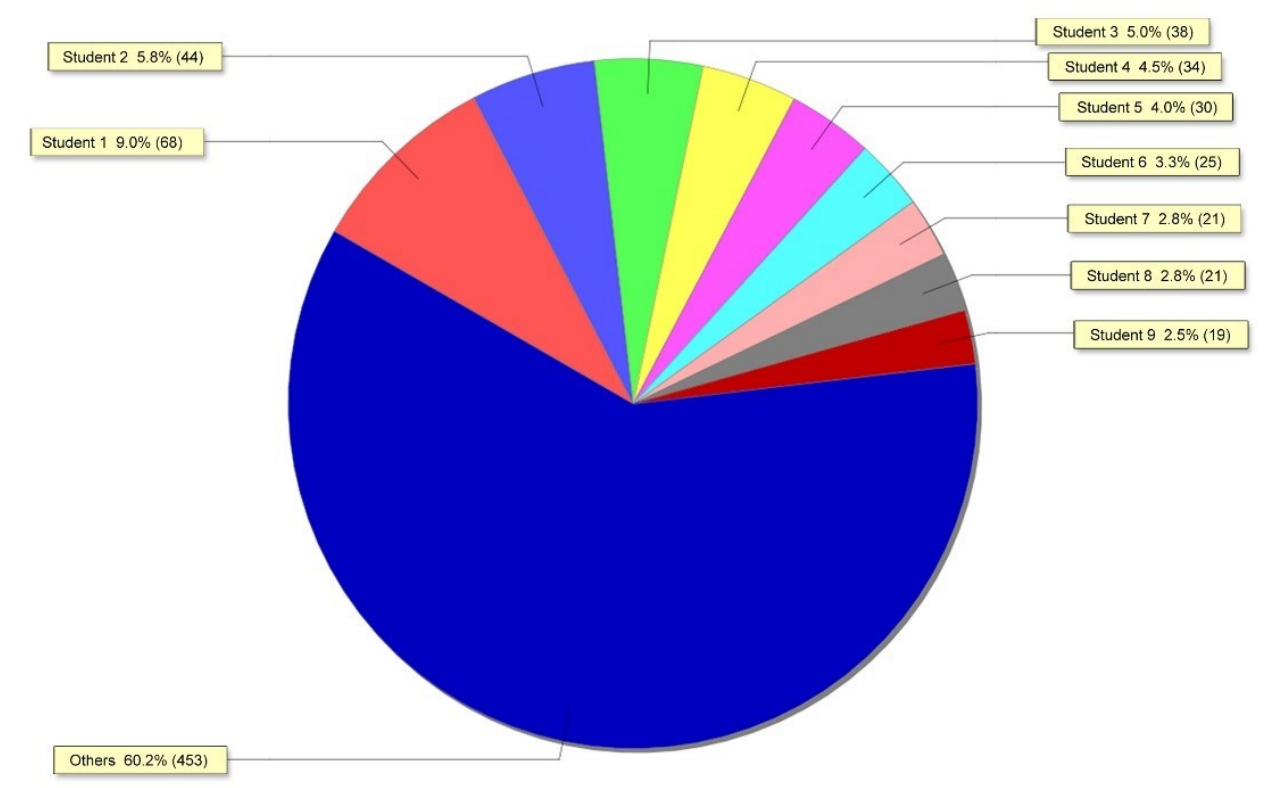

Figure 9: A pie chart displaying the numerous eTools used on the platform for the duration of the project, and can be seen that the DF and External Tool (RR) eTools comprised of 753 and 589, respectively of the total usage of eTools

\section{Discussion}

The DF was used with the intention of providing the students in this study with a platform where learning technologies could be explored. The utilization of DF permits the academic teaching-and-learning participants to work as a group or on an individual basis to participate in online discussions, which in this case focused on 
nuclear energy plants. Their findings (or contributions) were visible to the group members within the group and the other group, i.e. Group 1.1 and Group 1.2 as seen in Figure 1.

An added benefit to the utilization of DF is that the student contributions can be done from any geographical location, with numerous electronic devices with a stable reliable internet connection. Students were asked to contribute and participate in the online discussion, to prompt further discussion about the topic amongst their peers, which is listed in the topic under the forum, entitled, nuclear power for sustainable future in South Africa (see Figure 2). The group size was limited to six students max for ease of online invigilation and to allow for more engaging group involvement.

Furthermore, regular online engagement within a DF regarding any given topic at hand iterates that students should not only be involved in the online space but should also grasp the theory content. If the students do the latter, they should create understanding via communal feedback, which in turn will increase their understanding of the theory section. This productive learning-and-teaching initiative using a communication qualitative assessment educational technology tool, called, DF, allowed the students to construct knowledge and to support their arguments by uploading sources to their counterclaims. The findings would support the work by Jonassen (Jonassen, 1994) in that it shows that the use of DF is not only seen as a communication tool within an LMS but it could also be considered to be a cognitive tool that enables 'cognitive learning strategies and critical thinking' amongst online participants and therefore allows for learning beyond the classroom.

In agreement with Markel (Markel, 2001), the constant interaction amongst the students in the form of posting comments, replying to posts, reading their peers' post, and uploading of sources involves numerous educational processes from 'reflection and the construction and re-construction of domains of knowledge' which allows for deeper learning and affords the student an opportunity to refine their thinking and let their voices' to be heard.

\section{Conclusion}

The first-year ECP physics students at the UWC discussed the debatable topic of whether South Africa should extend its nuclear footprint. An external LTI educational tool, named RR was designed, developed, implemented, and ultimately embedded onto the university's LMS to assist the students to move away from an argumentbased opinion to an opinion that is based on peer-reviewed sources (references). RR can quantify the number of times a student uses a reference and the number of different references used in their online debate. To ensure the longevity and maximum engagement in the discussion students were provided with a rubric.

Analyzing the discussion threads, it is encouraging to see how the students engaged with the educational tool, their peers, and the debatable topic nuclear power for sustainable future in South Africa. The results from the feedback form, the discussion threads, and the LMS statistics strongly suggest that the RR tool improves the communication skills of students for scientific research discussion purposes. The DF allowed the students to participate effectively in their own time and free to express their views with their peers. An event, which will not easily happen, if this class activity was to be done face-to-face.

Some of the improvements to the online debate using RR will include allowing students who are in groups where the engagement is very low the option to participate in another group, allowing students to upload more than one reference at a time, incorporate an online rubric (making use of Google Apps), have a way of displaying who the winning group of the debate is, and then finally to poll the before and after debate answering the question, "should South Africa increase their nuclear footprint?".

\section{Acknowledgement(s), Funding, Author contribution and Ethics}

The authors wish to acknowledge the assistance and encouragement from colleagues in the physics extended curriculum programme and special efforts by the administrative assistant Justin Klaas. The authors wish to express their gratitude for the support from the Department of Physics and Astronomy and University of the Western Cape's Directorate of teaching and learning. Dr. Lynndle Square taught Physics 151 during the time of this investigation, came up with the idea of using an online debate to discuss the topic, and came up with the Reference Register concept. Mr. Valentino van de Heyde set up and monitored the eTool, Discussion Forum (DF) located within iKamva and Mr. Duncan Smith developed the Reference Register tool. All three authors contributed to the development of this paper and the collection and analysis of the data. The principal investigator and applicant for ethics 
clearance from the University of the Western Cape ethics committee was Dr. Lynndle Square, Ethics Reference Number: HS18/7/31. The authors declare that no competing interest exists.

\section{References}

Andresen, M. 2009. Asynchronous discussion forums: success factors, outcomes, assessments, and limitations. Journal of Educational Technology \& Society, 12 (1), pp249-257.

Cheese, F. 2015. Use online debates to enhance classroom engagement. In B. Chen, A deNoyelles \& K. Thompson (Eds.) Teaching Online Pedagogical Repository. Or- Orlando, FL: University of Central Florida Center for Distributed Learning. Available through https://topr.online.ucf.edu/use-online-debates-to-enhance-classroom-engagement/

Davis, K., Zorwick, M., Roland, J., and Wade, M., 2016. Using debate in the classroom: encouraging critical thinking, communication, and collaboration. Taylor \& Francis.

Fleming, D. 2008. Using best practices in online discussion and assessment to enhance collaborative learning. College Teaching Methods \& Styles Journal, 4 (10), pp. 21-40.

Giannakos, M., and Lapatas, V., 2010. Towards Web 3.0 concept for collaborative eLearning.Multi-Conference on Innovative Developments in ICT, 10, pp. 147-151.

Hazari, S., 2004. Strategy for assessment of online course discussion. Journal of Information Systems Education, 15 (4), pp 349-355.

Johnson, D.W., Johnson, R.T., and Smith, K.A., 2006. Active learning: Cooperation in the university classroom (3rd edition). Edina, MN: Interaction.

Johnson, D.W., Johnson, R.T. and Smith, K.A., 2014. Cooperative learning: Improving university instruction by basing practice on validated theory. Journal on Excellence in University Teaching, 25(4), pp.1-26.

Jonassen, D., 1994. Technology as cognitive tools: learners as designers. ITForum Paper, 1, pp. 67-80.

Kennedy, R., 2007. In-class debates: Fertile ground for active learning and the cultivation of critical thinking and oral communication skills. International Journal of Teaching \& Learning in Higher Education, 19(2).

Maiorana, V., 1992. Critical thinking across the curriculum: building the analytical classroom.: ERIC Clearinghouse on Reading and Communication Skills.

Markel, S. and Elementary Education ECl., 2001. Technology and education online discussion forum. Online journal of distance learning administration, 4.

McGreevy, P., Tzioumis, V., Degeling, C., Johnson, J., Brown, R., Sands, M.,. . . and Phillips, C. (2017). The use of a virtual online debating platform to facilitate student discussion of potentially polarising topics. Animals, 7 (9), pp. 68.

Miranda, P., 2017.Validation of an e-Learning 3.0 critical success factors framework: a qualitative research. Validation of an eLearning 3.0 critical success factors framework: a qualitative research, 1, pp. 339-363.

Nandi, D., Chang, S., and Balbo, S., 2009. A conceptual framework for assessing interaction quality in online discussion forums. Same places, different spaces. Proceedings ascilite Auckland, pp. 7-23.

Paul, R and Elder, L., 2019. The miniature guide to critical thinking concepts \& tools. Rowman \& Littlefield.

Rubens, N., Kaplan, D., and Okamoto, T., 2012. E-Learning 3.0: anyone, anywhere, anytime, and Al. In International Conference on Web-Based Learning, pp. 171-180.

Scott, S., 2008. Perceptions of students' learning critical thinking through debate in a technology classroom: A Case Study. Journal of Technology Studies, 34 (1), pp. 39-44.

Shaw, J. A., 2012. Using small group debates to actively engage students in an introductory microbiology course. Journal of Microbiology \& Biology Education: JMBE, 13(2), pp. 155.

Tessier, J. T., 2009. Classroom debate format. College Teaching, 57 (3), pp. 144-152.

The University of the Western Cape., 2009. Graduate attributes and the strategic plan for teaching and learning. Graduate attributes and the strategic plan for teaching and learning. Available through https://www.uwc.ac.za/TandL/Pages/Graduate-Attributes.aspx.

Zare, P., and Othman, M., 2013. Classroom debate as a systematic teaching/learning approach. World Applied Sciences Journal, 28 (11), 1506-1513. 